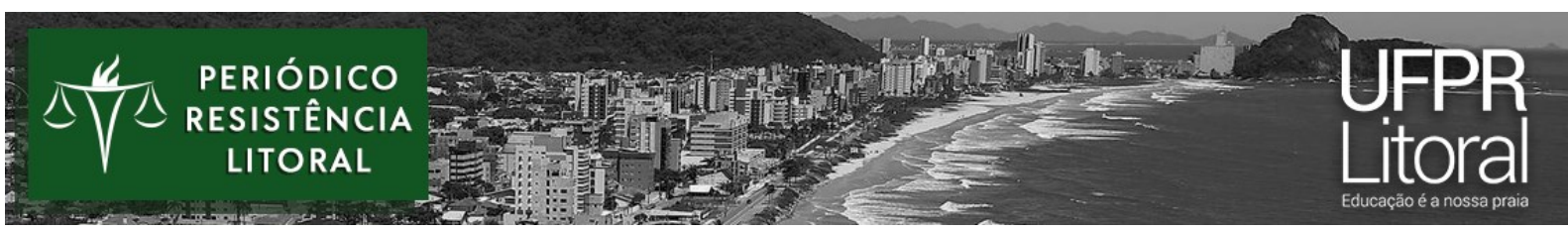

\title{
A QUESTÃo AGRÁRIA NO BRASIL: da invasão ao século XXI uma história de espoliação.
}

\author{
Vanessa Fiorini ${ }^{1}$
}

\begin{abstract}
Resumo: O Brasil vivenciou um contraditório processo de crescimento e desenvolvimento econômico. Desde a invasão Portuguesa passando pela Lei de Terras, pela industrialização, a questão agrária permanece inalterada em detrimento do avanço das contradições econômicas e sociais geradas pelo capitalismo. O padrão de organização da agricultura, heranças da economia colonial, revelou capacidade notável de resistir à força do tempo-espaço e de opor-se a democratização do campo e a preservação de biomas, florestas e territórios tradicionais. Assim a histórica estável estrutura fundiária representa a perfeita harmonia entre latifúndio e modernização técnica, evidenciando a importante correlação entre a superexploração capitalista e o agronegócio. Este escrito busca, a partir de um diálogo coletivo fruto da vivência, participação e estudos sobre tempos-espaços do mundo rural, resgatar o processo sócio histórico da questão agrária e sua contemporaneidade no Brasil, evidenciando as contradições advindas desse modelo de desenvolvimento embasado nos interesses do grande capital e no latifúndio.

Palavras-chave: Questão agrária, capitalismo e reforma agrária;
\end{abstract}

Abstract: Brazil has experienced a contradictory process of economic growth and development. Since the Portuguese invasion, the Land Law, and industrialization, the agrarian issue has remained unchanged at the expense of the advance of economic and social contradictions generated by capitalism. The pattern of organization of agriculture, inherited from the colonial economy, has revealed a remarkable capacity to resist the force of time-space and to oppose the democratization of the countryside and the preservation of biomes and forests. Thus, the historical and stable land structure represents the perfect harmony between latifundia and technical modernization, evidencing the important correlation between capitalist overexploitation and agribusiness. This paper seeks, from a collective dialogue resulting from the experience, participation, and studies about the times-spaces of the rural world, to rescue the socio-historical process of the agrarian issue and its contemporaneity in Brazil, highlighting the contradictions arising from this development model based on the interests of big capital and latifundia.

Palavras-chave: Questão agrária, capitalismo e reforma agrária;

\footnotetext{
${ }^{1}$ Mestre em Serviço Social pela Universidade Federal de Santa Catarina - UFSC; Assistente Social na APAE Balneário Camboriú - SC - e-mail: vanessa_fiorini@yahoo.com.br
} 


\section{INTRODUÇÃO}

O texto que segue é resultante do conhecer, participar e vivenciar coletivamente temposespaços do mundo rural e carrega consigo a necessidade de tornar o diálogo coletivo travado nessa caminhada, vivo e presente nas inquietações sociais.

Assumimos que é preciso uma vez mais contar a história da questão agrária brasileira! Adiantamos, que não nos guiaremos pela versão da história dos "conquistadores", figurada tantas vezes nos livros de história, que nos coloca no patamar de país descoberto e conquistado, da ordem e do progresso, mas sim contaremos a versão dos que estavam do outro lado da conquista, "os conquistados", aquela que reconhece como se deu (e ainda se dá) o processo de espoliação ${ }^{2}$ resultante da sede monetária capitalista imperialista que busca com ferocidade consolidar modelos produtivos rentáveis e eficientes.

Há algumas décadas, na história brasileira, a questão agrária é permanente nas inquietações sociais e políticas, tem sido uma questão que regressa ciclicamente na história do país, expressando às suas contradições, polarizando os conflitos e complicando nosso processo histórico. Como diria José de Souza Martins (2000), temas como este limitam a possibilidade de sairmos dos impasses que nos aprisionam numa modernidade em que o atraso se faz presente.

A questão da terra (e também do território) na realidade brasileira é um problema ainda não resolvido, as pessoas, camponesas e camponeses, as comunidades de povos indígenas e quilombolas e outros, que dela necessitam para sobreviver, têm e tiveram historicamente o seu direito cerceado por uma pequena parcela de capitalistas que detém grandes quantidades de terra e dela retiram seu lucro e seu status através da exploração de muitos trabalhadores e trabalhadoras e dos territórios tradicionais e florestas.

Isso se comprova ao olharmos por exemplo os dados do último levantamento sobre a distribuição de terras agricultáveis no país, de acordo com o último Censo Agropecuário realizado em 2017, cerca de apenas 1\% dos estabelecimentos rurais com áreas acima de 500 hectares controlam mais de 50\% da área rural agricultável do país, enquanto estabelecimentos com áreas menores a 10 hectares representam metade dos estabelecimentos rurais, mas controlam apenas $2 \%$ da área total agricultável.

\footnotetext{
${ }^{2}$ Em termo jurídico "Ato de privar alguém de algo que lhe pertence ou a que tem direito por meio de fraude ou violência".
} 


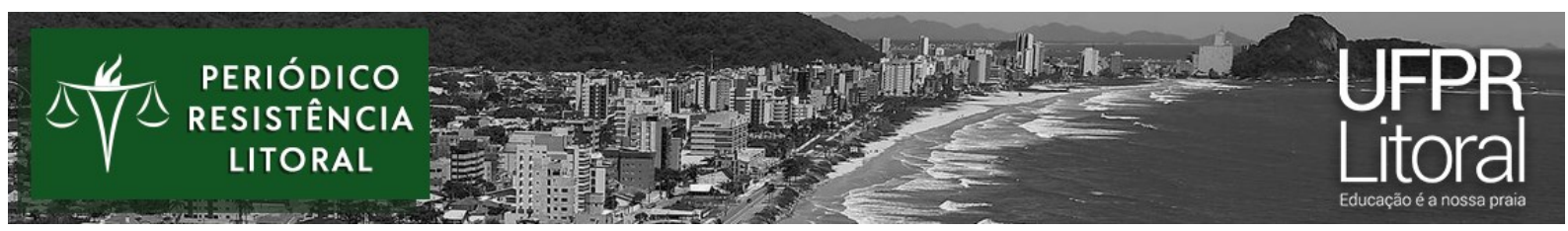

Ainda os dados da demarcação de terra indígenas têm acompanhado a letargia do olhar em relação a estrutura fundiária e produtiva do país, de acordo com publicação do CIMI cerca de $41 \%$ das terras indígenas permanecem sem providências e apenas $30 \%$ do total foram demarcadas.

Diante desse quadro, é recorrente a afirmativa entre autoras e autores da literatura sobre a questão agrária que, no caso brasileiro, a forma como ocorreu à apropriação de terras, as relações baseadas no escravismo e o desenvolvimento do capitalismo no campo, foram fatores determinantes, dentre os demais, para a construção de uma estrutura agrária concentrada que teve como consequências o aumento da pobreza rural e urbana contribuindo para quadro de extrema desigualdade que ainda hoje se gesta e para o intenso processo de ocupação e espoliação dos territórios tradicionais e de seus povos.

\section{INVADIR E ESPOLIAR: traços da "conquista" nas Terras Brasileiras - 1500 A 1920}

A origem da formação social brasileira ocorre na condição de Colônia de Portugal, por ocasião das expansões marítimas do período. Assim os portugueses quando invadiram o território do Brasil no ano de 1500, o fizeram a partir do financiamento emergente capitalismo comercial $^{3}$ europeu e por sua vez tomaram o poder territorial, passando a escravizar as populações tradicionais e originárias que aqui viviam, submetendo tudo (natureza) e todos (pessoas) às leis da coroa portuguesa.

\footnotetext{
Atrás dos portugueses lançam-se os espanhóis. Escolheram outra rota: pelo Ocidente, ao invés do Oriente. Descobrirão a América, seguidos de perto pelos portugueses que também toparão com o novo continente. Virão depois dos países peninsulares, os franceses, ingleses, holandeses, até dinamarqueses e suecos. A grande navegação oceânica estava aberta, e todos procuravam tirar partido dela. (PRADO JR. 1981, p.11)
}

\footnotetext{
${ }^{3}$ Neste caso nos valemos da perspectiva de Caio Prado Junior, para ele o Brasil nasce capitalista, não havendo a necessidade de uma revolução como a ocorrida no continente para substituir o sistema Feudal. Para Prado Junior, os acontecimentos dessa fase histórica, como a expansão marítima a europeia, os descobrimentos foi um capítulo da história do comércio europeu, impulsionado pela imensa empresa comercial a que se dedicam os países da Europa a partir do século XV. Os "descobrimentos", deram origem as colônias que alimentavam a grande empresa comercial europeia de produtos de elevada demanda comercial. Vale destacar que a colonização da América no século XVI, é consequência da continuidade da expansão marítimo-comercial que contribuiu para o crescimento da economia capitalista europeia. (PRADO JR., 1980 p. 6-7)
} 


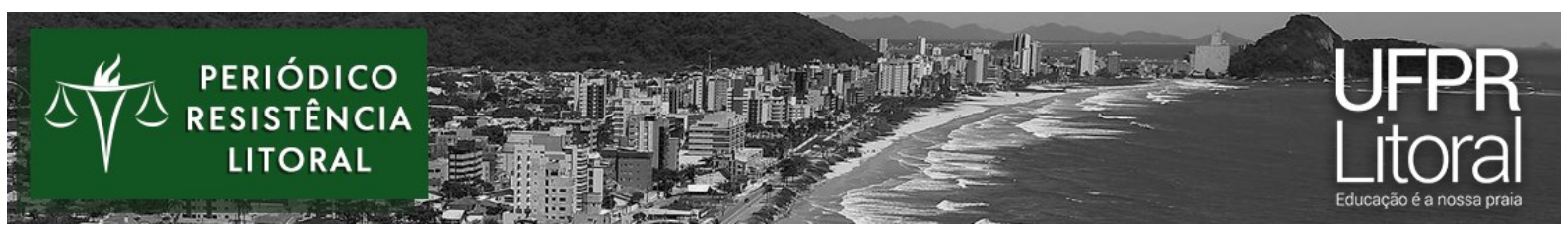

Muitos foram os fatores que levaram os países do "velho mundo" a empreitada das expansões marítimas porém, de acordo com Prado Jr. (1981, p.11) "todos os grandes acontecimentos desta era a que se convencionou chamar de "descobrimentos", articulam-se num conjunto que não é senão um capítulo da história do comércio europeu".

Deste ponto de vista, é possível compreender o olhar com que os povos da Europa ${ }^{4}$ abordaram a América, o olhar de países que viam somente as riquezas que aqui residiam para explorar, mas consideravam um território primitivo com nenhuma "civilidade" ou atrativos que intencionassem a povoa-lo inicialmente. Porém, os portugueses, pressionados pela possibilidade de os franceses ocuparem espaços formando colônias de povoamentos nas novas terras, se viram obrigados a realizar um esforço para ocupá-las permanentemente. Ressalta-se que a forma de ocupação do território brasileiro foi em grande medida baseada nas características geográficas indicando que em cada região, o clima, o solo, o relevo, produtos espontâneos (pau-brasil por exemplo), determinavam um maior ou menor povoamento das áreas.

É este o verdadeiro sentido da colonização tropical, de que o Brasil é uma das resultantes; [...]. Se vamos à essência da nossa formação, veremos que na realidade nos constituímos para fornecer açúcar, tabaco, alguns outros gêneros; mais tarde, ouro e diamante; depois algodão, e em seguida café, para o comércio europeu. Nada mais que isto. É com tal objetivo, objetivo exterior, voltado para fora do país e sem atenção a considerações que não fossem o interesse daquele comércio, que se organizarão a sociedade e a economia brasileiras. Tudo se disporá naquele sentido: a estrutura social, bem como as atividades do país. (PRADO JR., 1985, cap. 01, n.p)

Após a invasão até o ano de 1530, a atividade de exploração do pau-brasil foi suficiente para satisfazer os interesses extrativistas europeus, porém, após esse período o pau-brasil que havia no litoral brasileiro esgotou-se, levando a Coroa a pensar em estratégias para além "das feitorias comerciais, tanto para explorar recursos, que não estavam ao alcance da mão à primeira vista, quanto para defender e ampliar as fronteiras do território" (SANTOS, 2012, p. 56).

Pois bem, o Brasil além da grande quantidade de minérios tinha grande potencial para produção de produtos agrícolas e isso logo fora percebido pelos colonizadores, que passaram a organizar as terras para produzir mercadorias buscando atender os interesses comerciais da metrópole portuguesa voltados para o mercado externo europeu, a partir de então, tudo se transformava em mercadoria e visava o lucro. "Tal modelo de produção, sob a égide das leis do

\footnotetext{
${ }^{4}$ De acordo Prado Jr. (1985, cap. 01, np) “A ideia de povoar não ocorre inicialmente a nenhum”.
} 
capitalismo produzindo apenas produtos agrícolas e minerais para abastecimento do mercado europeu, foi denominado pelos historiadores de modelo agroexportador” (STÉDILE, 2011, p.20).

O modelo de exploração adotado foi o plantation a forma de apropriação de terras utilizada pelos europeus foi o monopólio da propriedade de todo território pela Coroa. Para que o modelo agroexportador surtisse efeito a Coroa concedeu o uso das terras, com direito hereditário e sem direito a venda, aos capitalistas que se interessavam em investir seu capital no Brasil, tendo como critério que o investidor produzisse os produtos que seriam exportados para o mercado europeu.

O regime de propriedade era o da livre ocupação das terras devolutas, tendo seu reconhecimento formal através do título de sesmarias. Assim surgem os latifúndios escravistas que combinavam a necessidade de explorar com a falta de mão de obra na colônia criando assim um rentável mercado de tráfico de escravos.

Nesse caminhar da invasão até aqui, já podemos perceber a relação entre ocupação do território e exploração econômica das potencialidades evidenciando uma colonização predatória "cujas atividades entravam em colapso por falta de investimentos e melhoramentos técnicos - um contrassenso sem chances de competir num mundo que descobre cada vez mais formas de controle da natureza pela ciência" (SANTOS, 2012, p 58).

Esse processo legou à nossa formação social, além das demais características: as grandes propriedades territoriais agrárias, consequências de uma agricultura da monocultura estimulada pelos interesses comerciais europeus.

No início do século XIX o regime de sesmarias é extinto e como não havia outra legislação que regulasse a posse das terras devolutas ocorre uma rápida expansão dos sítios de pequenos produtores. É então em meados desse mesmo século que o regime escravocrata começa a entrar em decadência. As pressões para abolição da escravatura e, consequentemente, para substituir o trabalho escravo pelo assalariado pressionam a Coroa que promulga em 1850 a primeira lei de terras do Brasil - Lei no 601 de 1850 - que "implanta", se assim podemos dizer, a propriedade privada de terras no país fundamentando juridicamente a transformação da terra em mercadoria.

Para Silva (1981, p.10): 


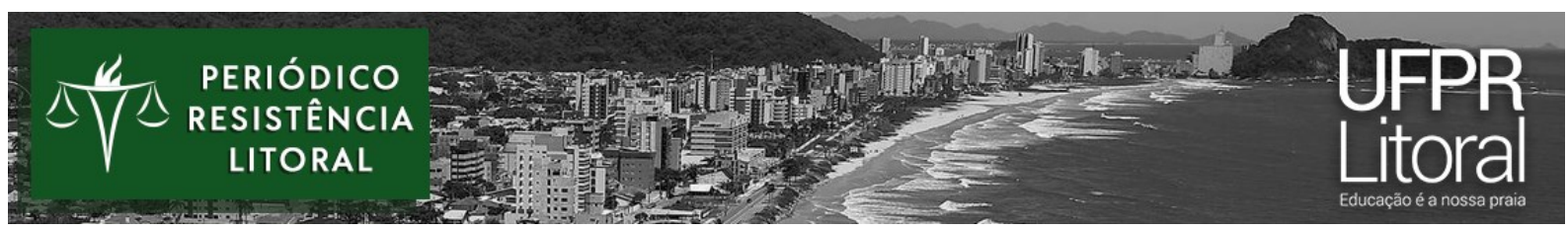

A Lei de Terras, como ficaria conhecida que rezava que todas as terras devolutas só poderiam ser apropriadas mediante a compra e venda, e que o governo destinaria os rendimentos obtidos nessas transações para financiar a vinda de colonos da Europa. Matavam-se, assim, dois coelhos com uma só cajadada. De um lado, restringia-se o acesso às terras (devolutas ou não) apenas àqueles que tivessem dinheiro para comprálas. De outro, criavam-se as bases para a organização de um mercado de trabalho livre para substituir o sistema escravista.

Em 1888 finalmente é promulgada a Lei Áurea que "liberta", em tese, todos os trabalhadores escravizados. Assim, diante do impedimento dos ex escravos se tornarem camponeses e camponesas, estes vão buscar nas cidades alternativas para sobreviverem agora podendo vender sua força de trabalho, vale ressaltar que as condições de trabalho da população negra não se distanciavam, muitas vezes, das condições da escravidão antes vivenciada, apenas assumia outras roupagens.

Com o fim do escravismo, o modelo agroexportador dependente do trabalho escravo entra em crise, dando fim ao modelo plantation. Os donos dos latifúndios, precisavam então substituir esta mão de obra e a alternativa encontrada foi uma intensa propaganda na Europa com objetivo de atrair camponesas e camponeses europeus para trabalharem no Brasil, estes que vieram em número praticamente igual ao número de trabalhadores ex-escravos. Surge assim um novo regime de produção: o colonato. Esse regime só entrará em decadência em meados da década de 1960, tendo como um dos fatores as mudanças provocadas pela promulgação do Estatuto do Trabalhador Rural em 1963.

O período de 1889 a 1930 no Brasil compreende a República Velha ou Primeira República e foi fortemente marcado pelo forte controle político, exercido sobre o governo, da oligarquia cafeeira paulista e da elite rural mineira, através da famosa "política do café com leite". Cabe salientar que é a partir desse momento que se desenvolve com mais força o coronelismo, prática que garantia poder político regional às diversas elites locais do país. Também uma das características desse momento no Brasil é a ascensão e queda do modelo econômico agroexportador com base no café e o acúmulo de capitais a partir da exportação que impulsionam o início da industrialização no país.

Dessa forma, com a crise das oligarquias rurais e a crise econômica mundial ${ }^{5}$, atingindo profundamente a produção cafeeira, a elite reuniu os motivos para derrubar os fazendeiros

\footnotetext{
${ }^{5}$ Cabe sinalizar no que tange a crise econômica, esta chamada de Grande Depressão, ou de Crise de 1929, foi uma expressiva depressão econômica que persistiu ao longo da década de 1930, finalizando somente com a Segunda Guerra Mundial. O dia 24 de outubro de 1929 é considerado popularmente o início da Grande Depressão,
} 


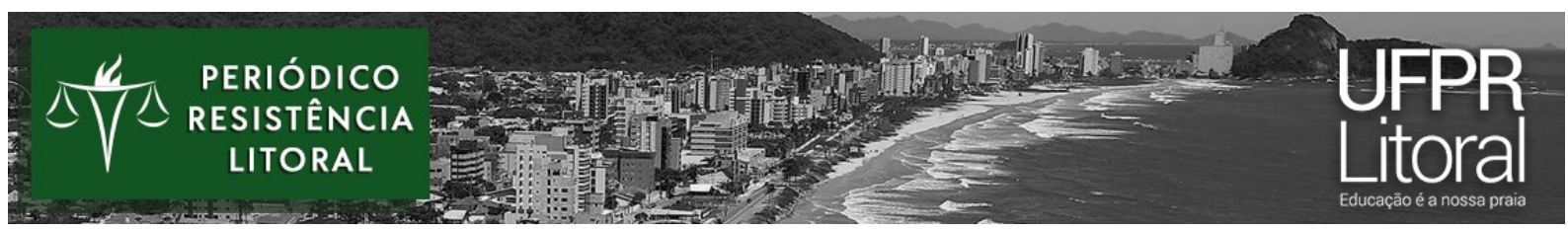

paulistas que estavam no poder, através da Revolução de 1930. Assim a República Velha chega ao fim dando início a Era Vargas.

\section{A SUBMISSÃO DA AGRICULTURA A INDÚSTRIA - 1930 A 1980}

Juntamente à crise do modelo agroexportador, se instaura também, uma crise política institucional no país, assim, entramos na década de 1930, com a união da burguesia industrial, que a partir de um golpe, tomam o poder da oligarquia rural exportadora.

O período que segue entre os anos de 1930 a 1950 marcam uma nova fase da economia brasileira onde o setor industrial vai cada vez mais se consolidando, é nesta fase que são implantadas a indústria pesada no país, siderurgia, petroquímica, material elétrico, etc. Esta etapa, no que tange a questão agrária, é de subordinação política e econômica da agricultura à indústria, crescendo a visão empresarial da propriedade e incentivando-se a agricultura mercantil.

Industrializada as cidades, precisava-se então "industrializar a agricultura", conforme aponta Silva (1981, p.11)

No início dos anos sessenta, que corresponde ao final da fase de industrialização
pesada no Brasil, instalam-se no país as fábricas de máquinas e insumos agrícolas.
Assim, por exemplo, são implantadas indústrias de tratores e equipamentos agrícolas
(arados, grades, etc.), fertilizantes químicos, rações e medicamentos veterinários, etc.
Evidentemente a indústria de fertilizantes e defensivos químicos só poderia se instalar
depois de constituída a indústria petroquímica; a indústria de tratores e equipamentos
agrícolas, depois de implantada a siderurgia; e assim por diante. O importante é que,
a partir da constituição desses ramos industriais no próprio país, a agricultura
brasileira iria ter que criar um mercado consumidor para esses "novos" meios de
produção.

O quadro que se apresenta na década de 1960 é de uma agricultura "moderna" e de intensa submissão dos camponeses ao capital industrial. Vale sinalizar que a modernização tecnológica ocorre simultaneamente à modernização das relações de trabalho, que serão formalizadas pelo o Estatuto da Terra em $1964^{6}$, este que fora criado em pleno governo militar

quando os valores das ações na bolsa de Nova Iorque caíram drasticamente. A quebra na bolsa piorou significativamente os efeitos da recessão já existente, causando grande deflação e queda nas taxas de venda de produtos, que por sua vez obrigaram o fechamento de inúmeras empresas comerciais e industriais, elevando as taxas de desemprego.

${ }^{6}$ Conforme Art. $1^{\circ}$ da Lei 4.504 de 30 de novembro de 1964. Esta Lei regula os direitos e obrigações concernentes aos bens imóveis rurais, para os fins de execução da Reforma Agrária e promoção da Política Agrícola. 


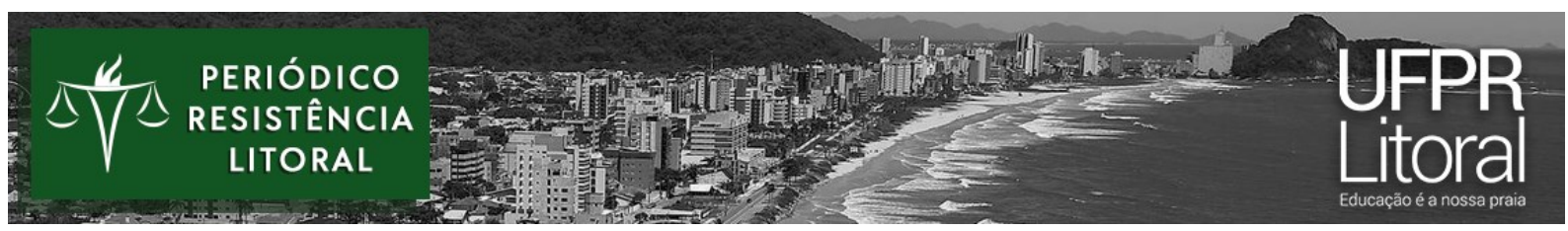

entrelaçado a uma profunda crise econômica vivenciada no Brasil, contudo durante o mesmo período esta legislação foi ineficaz devido a letargia com a qual o governo olhava para a questão da terra.

Com a entrada dos militares do poder, - através de um golpe amplamente financiado pelos $\mathrm{EUA}^{7}$ - , mantinha-se a retórica do discurso acerca do atraso da agricultura em um país de grande "vocação agrária", assim os militares " tomaram para si o desafio de levar o desenvolvimento para o espaço rural, sendo este considerado imperativo para o avanço do país como um todo" (COSTA, 2013, p.44).

Ocorre que as estratégias adotadas para tal desenvolvimento não contemplaram a mudança da estrutura fundiária, a opção foi a adoção de mecanismos de modernização na base técnica produtiva (insumos, venenos, máquinas) advindos da Revolução Verde, tendo como consequência a manutenção e beneficiamento tanto dos interesses das elites industriais quanto dos grandes latifundiários em detrimento do avanço do êxodo rural e da desigualdade e pobreza no campo. Nesse sentido Ianni, (1981, p.90) aponta que "a agricultura foi transformada em um mercado importante e crescente para a produção do setor industrial, principalmente máquinas, implementos agrícolas, fertilizantes e defensivos".

Mas o processo de modernização teve impactos profundos:

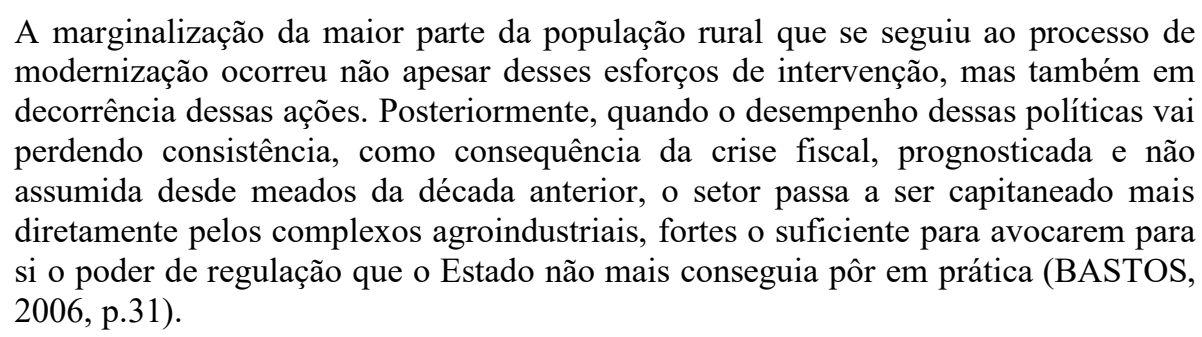

Diante deste quadro de espoliação dos camponeses e camponesas do campo, formavase o consenso sobre a injusta situação da trabalhadora e do trabalhador rural, a injusta divisão de terras no país elevando a consciência política das massas camponesas e isso passa a representar uma ameaça aos interesses dos grandes latifundiários que promovem a expulsão em massa dos trabalhadores rurais passando a reestruturar o trabalho nas fazendas com pouca mão de obra e muitas máquinas.

\footnotetext{
${ }^{7}$ Sugestão de documentário para compreender a ditadura militar brasileira: O dia que durou 21 anos.
} 


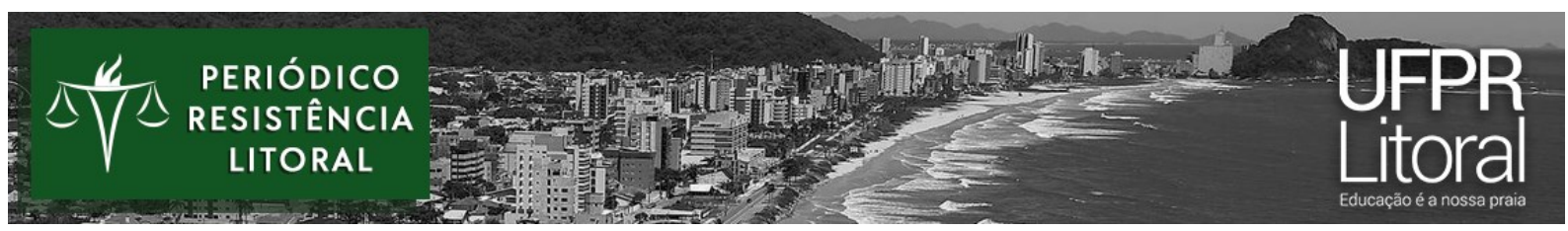

Entramos da década de 1970 com uma industrialização da agricultura acelerada, Silva (1981) aponta três grandes modificações que marcaram profundamente a agricultura brasileira nesse período: o fechamento das fronteiras agrárias, o processo acelerado de modernização da agricultura no Centro-Sul do país e a crescente presença do capitalismo monopolista no campo.

O período que segue até os anos de 1982 é marcado pelo desenvolvimento de uma agricultura capitalista integrada com a economia industrial urbana e externa mediada financeiramente pelo setor público regida pelas leis dos grandes monopólios. Delgado (2005, p. 58) aponta que:

Nesse período as funções da agricultura na economia, mais além de perseguirem
objetivos estritos a estabilidade de preços, do saário real e do superávit comercial
externo, incorporarão uma outra demanda, não presente no período anterior: o
aprofundamento das relações técnicas da agricultura com a indústria e de ambos com
o setor externo, isso tudo fortemente subvencionado pela política agrícola e comercial
do período.

Portanto a década de 1980 foi caracterizada, nos países centrais do capitalismo, pela reestruturação produtiva do capital monopolista e pela manutenção de um Estado que possibilitasse o enfraquecimento da organização da classe trabalhadora e alçasse o grande capital. No que tange a questão agrária no Brasil, essa década representou um momento contraditório e de transição pois durante o regime militar não se tinha espaço para a discussão da questão agrária em nenhum âmbito seja ele político ou acadêmico.

Com a abertura política a partir da Constituição Federal de 1988 se inicia um jogo político no sentido do ordenamento constitucional e também um processo de "ajustamento constrangido" que se caracteriza por restrições de ordem interna e externa, expressas pelo endividamento público e dependência internacional promovendo a estagnação econômica do país nesta década.

Vale destacar que a agricultura brasileira dos anos de 1965 a 1981 completou um ciclo de crescimento e modernização técnica, não alterando a sua estrutura agrária.

Os anos que seguem na década de 1990 e anos 2000 é possível verificar, que não houve mudanças na estrutura agrária brasileira. Na atualidade ainda se mantém a desigualdade, mesmo com o novo ordenamento de direito agrário que prescreve o princípio da função social da propriedade fundiária. Os procedimentos e omissões da política fundiária do Poder Executivo e dos demais poderes de Estado arbitram contraditoriamente a reprodução dessa desigualdade. 


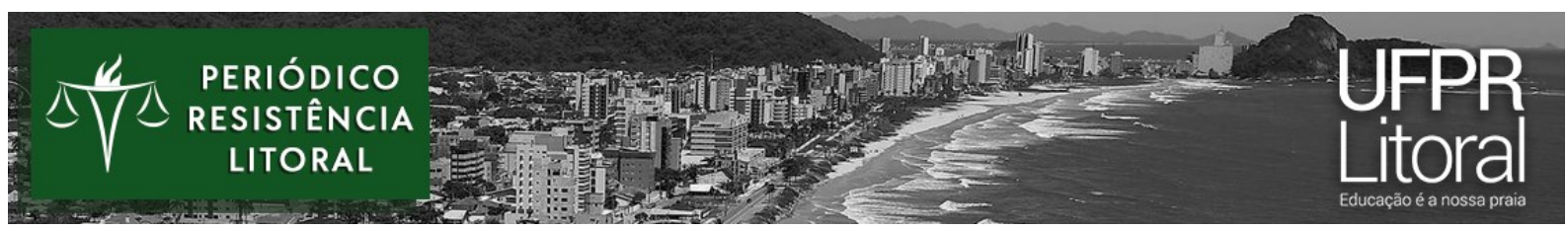

\title{
3. "E A TAL REFORMA AGRÁRIA QUE É TANTO COMENTADA?"
}

A luta pela reforma agrária é uma das lutas populares mais expressivas da atualidade. Mas as elites e alguns setores governamentais como também a mídia tem se mostrado contrário a esses movimentos, colaborando com um amplo processo de criminalização dos movimentos sociais do campo, vale citar a pouco tempo a revisão ainda em tramitação da Lei Antiterrorismo (Lei 13.260/2016) que situa a atuação e lutas de alguns movimentos sociais no campo do terrorismo ${ }^{8}$.

Conforme Leal (2002):

\begin{abstract}
A luta pela reforma agrária, no Brasil, tem sido historicamente não apenas uma tentativa de resolução satisfatória da ainda não resolvida questão agrária, mas também uma ponte para discussões em torno da distribuição de poder no país. Esta característica foi introduzida pelas Ligas Camponesas, na década de 50, e desde a década de 80, tem sido levada adiante especialmente pelo Movimento dos Trabalhadores Rurais Sem-Terra (MST).
\end{abstract}

Resgatando a história, no período de 1940 a 1960, é importante sinalizar o surgimento das Ligas Camponesas. Estas se constituíram em associações de trabalhadores rurais criadas inicialmente no estado de Pernambuco, posteriormente na Paraíba e no Rio de Janeiro, Goiás e em outras regiões do Brasil, exercendo intensa atividade no período que se estendeu de 1955 até a queda de João Goulart em 1964.

\begin{abstract}
As ligas surgiram na metade dos anos 50 para combater a exploração e a lida mais desumana a que estavam submetidos os trabalhos do campo, vítimas de um sofrimento imposto e patrocinado, sobretudo, por usineiros e senhores de engenho do setor canavieiro da Paraíba e de todo o Nordeste. Os trabalhadores queriam apenas estender a legislação trabalhista aos trabalhadores das usinas e dos engenhos. Era ter o direito de plantar e colher na terra que ele arrendava. (...) de pagar o foro em dinheiro e não através do cambão, também conhecido com 'canga', ou seja, o pagamento do aluguel da terra com dias de trabalho gratuito. As terras não passavam do entorno do próprio casebre, não mais do que uma pequena faixa ao redor da casinha de taipa onde o camponês e a família moravam, onde tinham que trabalhar 2, 3 ou até 4 dias, por semana, para o proprietário da terra. (ALMEIDA, 2015)
\end{abstract}

\footnotetext{
${ }^{8}$ Vale lembrar no governo FHC a criação da Medida Provisória (MP) $\mathrm{n}^{\mathrm{o}}$ 2.027-39, de $1^{\circ}$ de junho de 2000, que alterou as Leis 4.504/1964, 8.177/1991 e 8.629/1993 e o Decreto-Lei 3.365/1941, e foi considerada um marco para a reforma agrária, ficando conhecida como a "lei anti-invasão", pois sua finalidade era reduzir o número de invasões que vinha ocorrendo na década de 1990. A MP criou um conceito de "criminalização" das invasões/ocupações4 realizadas pelos movimentos sociais e isso foi determinante para reduzi-las (NASCIMENTO; SAES; ZYLBERSZTAJN, 2010).
} 


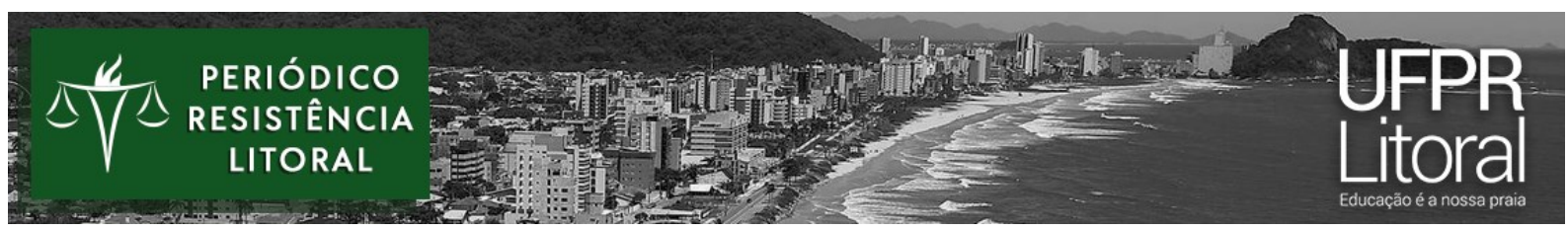

Destaca-se, de acordo com a literatura, que o debate em torno do histórico problema da terra inicia a rigor nos anos 1960, fator que demonstra o atraso no Brasil, que ficou quatro séculos de período colonial-escravocrata engessado em um modelo agroexportador.

Segundo Stédile (2005, p. 12):

Fomos o último país a abolir a escravidão (1888); um dos últimos países do continente a adotar a república como forma de governo (1899), imposta de forma medíocre por um golpe militar, pelos próprios militares que até então serviam à monarquia, república está dominada pelas mesmas elites rurais que se locupletavam durante o colonialismo.

Porém, com o fim do regime militar a partir de 1985 as forças sociais voltam a respirar após longa repressão do domínio autoritário e conservador da agricultura e:

Nesse contexto onde se vislumbram grandes mobilizações nas cidades brasileiras em torno da reconstrução democrática e da conquista de direitos, é que os trabalhadores rurais e urbanos também começam a se organizar em prol da luta pelo enfrentamento e resistência à reprodução capitalista no campo. (AZEVEDO, 2012, p.34)

Ou seja, enquanto formulavam-se planos governamentais para alterar as condições em que se encontrava o meio rural e a agricultura brasileira, os sujeitos pertencentes a este contexto se organizavam para confrontar as mudanças e para terem atendidas as suas bandeiras de luta. E é neste cenário que surgem alguns movimentos sociais do campo, sendo o mais expressivo: o Movimento dos Trabalhadores Rurais Sem Terra (MST).

De acordo com Santos (2009) em matéria extraída do site de notícias do MST:

\begin{abstract}
Alguns agravantes foram decisivos para esse processo de formação do MST, podendo ser citados a implantação do modelo econômico ditatorial, que tinha como meta implantar a rápida modernização da agricultura, com base na produção extensiva em propriedades privadas e, principalmente, pelo sistema de incentivos, créditos e subsídios. Com isso, a situação da agricultura familiar se encontrava em dificuldades devido à falta de políticas públicas que garantissem as condições dadas aos fazendeiros e latifundiários para este setor da sociedade. (grifo meu)
\end{abstract}

Destarte, o cenário que se colocava no Brasil, foi favorável para que os movimentos sociais amadurecessem um projeto próprio de reforma agrária, com a primazia da organização coletiva das lutas e expansão das reivindicações.

As pautas trazidas para o campo das negociações iam além das discussões em torno da oposição entre a pequena e a grande propriedade, evidenciando-se outros temas presentes no cotidiano do homem do campo - como a política de preços mínimos e a previdência rural. Em 1979 aconteceu o $3^{\circ}$ Congresso Nacional dos Trabalhadores 


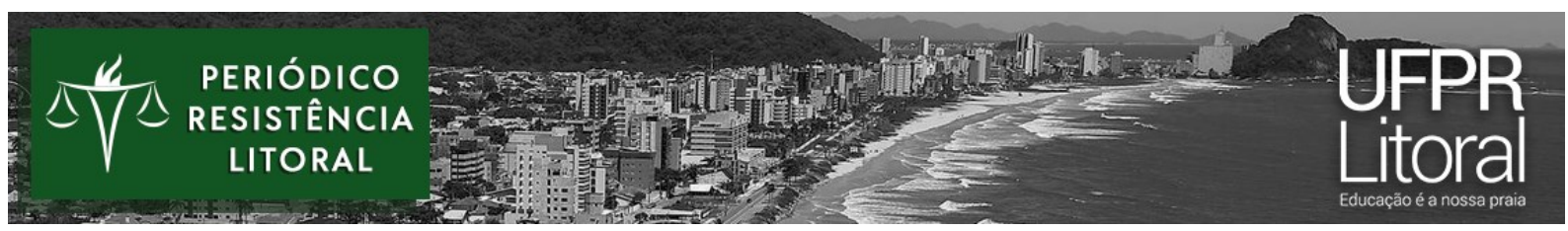

Rurais; em 1982 levou-se à frente a Campanha Nacional pela Reforma Agrária, que visava expandir a luta pela reforma agrária para outros setores da sociedade; em 1984 aconteceu o $1^{\circ}$ Encontro Nacional dos Sem Terra; e, em 1985 aconteceu o $4^{\circ}$ Congresso Nacional dos Trabalhadores Rurais. (COSTA, 2013, p. 51-52)

Vale salientar que no âmbito do poder político nesse período a reforma agrária volta a fazer parte das agendas políticas do Estado, traduzida inicialmente pelo I Plano Nacional da Reforma Agrária de 1985. Ocorre que "com a implantação do plano, passou a ocorrer forte luta entre a UDR (União Democrática Ruralista), o governo Sarney e os camponeses sem-terra, posseiros, etc. O objetivo da UDR foi a inviabilização da implantação do I PNRA". (OLIVEIRA, 2007; p. 126). Dessa forma o Governo Sarney, passou a utilizar do recurso ideológico da propaganda para alimentar falsas esperanças de que um dia a reforma agrária poderia acontecer. Assim, podemos dizer que o grande avanço desse período no que tange a questão da terra, foi o fato da Constituição Federal de 1988 (CF 1988), ter tornado a reforma agrária um dever fundamental do Estado.

\section{NA ERA DO AGRO, NADA É POP!}

A partir da década de 1990, entre os governos presidenciais de Itamar Franco e Fernando Henrique Cardoso a política econômica brasileira diante de um contexto econômico de crise, promoverá a desvalorização da renda da terra, concomitantemente a um novo endividamento externo que terá como consequência limite, uma crise de liquidez internacional. Diante de tal crise as elites vão recorrer a estratégias de sobrevivência já utilizadas anteriormente, o setor agrícola, promovendo um “jogo de cartas marcadas que experimentamos, e continuamos a jogálo na atualidade" (DELGADO, 2005; p.63) que irá reorganizar a questão agrária sob novos contornos.

Temos a partir desse momento a remontagem do agronegócio, senão como política estruturada e com algumas iniciativas que confluíram de acordo com Delgado (2005, p. 67) em:

(1) um programa prioritário de investimento em infraestrutura territorial com "eixos de desenvolvimento", visando à criação de economias externas que incorporassem novos territórios, meios de transporte e corredores comerciais ao agronegócio; (2) explícito direcionamento do sistema público de pesquisa agropecuária manifesto pela reorganização da Empresa Brasileira de Pesquisa Agropecuária, a operar em perfeita sincronia com empresas multinacionais do agronegócio; (3) regulação frouxa do mercado de terras, de sorte a deixar fora do controle público as "terras devolutas", 


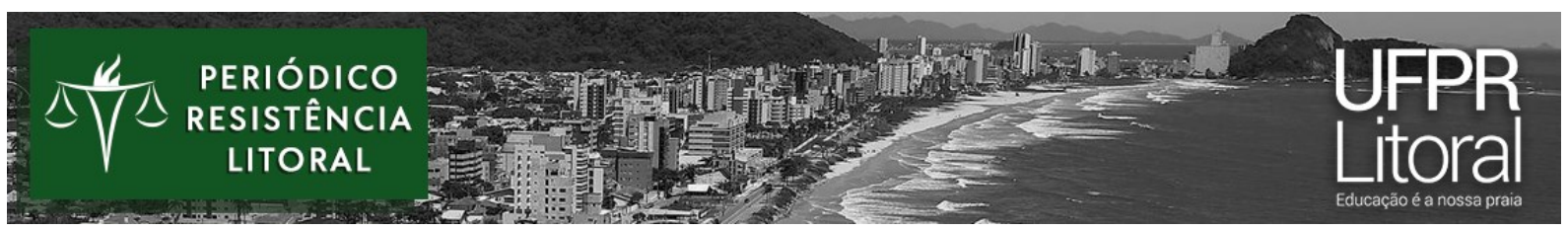

mais aquelas que declaradamente não cumprem a função social, além de boa parte das autodeclaradas produtivas; (4) mudança na política cambial, que ao eliminar a sobrevalorização tornaria o agronegócio competitivo no comércio internacional e funcional para a estratégia do "ajustamento constrangido".

O monocultivo de exportação: o agronegócio é assim chamado, pois:

Tratava-se de substituir e diferenciar a agri-cultura do agro-negócio. Ou por outras palavras, tratava-se de distinguir entre a atividade econômica milenar de produção dos alimentos necessários e fundamentais à existência da humanidade, e, a atividade econômica da produção de commodities (mercadorias) para o mercado mundial. (OLIVEIRA, 2007, p. 147)

Tal distinção propiciou aos intelectuais, novas concepções no sentido de forjar um conceito "de agricultura de pequeno porte voltada, parcial ou totalmente, para os mercados mundiais e/ou nacional, e integrada nas cadeias produtivas das empresas de processamento e/ou de exportação" (OLIVEIRA, 2007, p.147)

Pois bem surgia então uma concepção neoliberal para interpretar a agricultura de pequeno porte no Brasil, a agricultura familiar. $O$ neoliberalismo invadia não somente o mundo intelectual, mas também o mundo dos movimentos sociais e sindicais, na tentativa de eliminar a concepção de agricultura camponesa e junto os próprios camponeses.

Diante do exposto, na contemporaneidade, a questão agrária, conforme apontam Buainaim e Pires (2003) possui várias dimensões: a concentração da propriedade da terra, minifúndios e terras improdutivas (má utilização dos recursos produtivos); a situação da agricultura familiar; a expulsão de mão-de-obra; o mercado de terras restrito e problemas jurídicos; as famílias sem-terra constituindo a pobreza rural e urbana; os conflitos sociais e agrários; a invasão dos territórios tradicionais; o desmatamento com a expansão das fronteiras agrícolas e os problemas sociais.

A partir de 2003 com a eleição de Lula para presidente, o ambiente político, tornou visível três sujeitos a destacar: os movimentos sociais, os ruralistas e o governo. Dessa forma tínhamos de um lado os ruralistas, apreensivos com o atual governo e tecendo todo tipo de críticas e, de outro, os movimentos sociais de luta pela terra, entre eles o MST, que aproveitando a conjuntura intensificava suas ações no objetivo de avançar nas conquistas dos assentamentos. E o governo Lula por outro lado anunciava uma série de medidas dentre elas aprovação em 2003 do II Plano Nacional de Reforma Agrária - PNRA. 


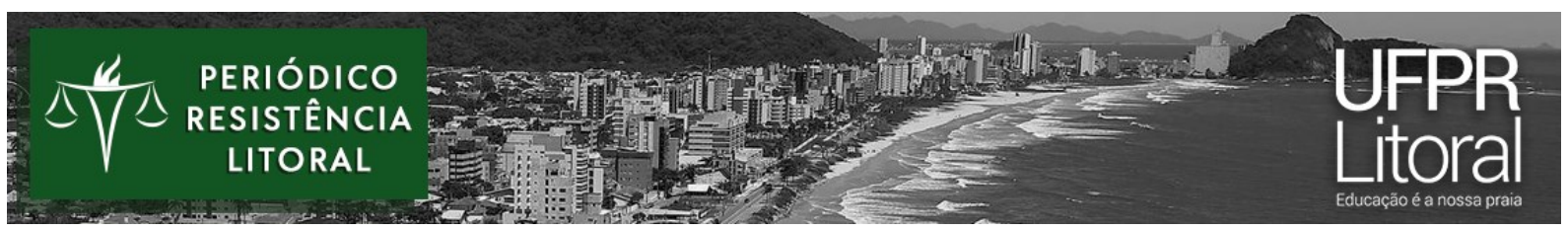

Os movimentos sociais, especialmente a CONTAG e o MST, centraram suas reivindicações no assentamento imediato das famílias acampadas por todo país e na revisão da legislação agrária, como na medida provisória que exclui da Reforma Agrária os trabalhadores que participam de ocupações e impede a vistoria das terras ocupadas e na atualização dos índices que medem a produtividade da terra. Por sua vez, os ruralistas, que ficaram tranquilos até os últimos anos voltaram a dar declarações contra o que denominam de ilegalidades e crimes contra a propriedade privada. (ALBUQUERQUE, 2006, p. 94)

Cabe sinalizar que antes da aprovação do II Plano, os trabalhadores rurais saíram em marcha unitária até Brasília, exigindo a aprovação do presente Plano, agregando as forças da CONTAG, MTS, Pastorais Sociais da Igreja Católica e o Movimento Terra e Liberdade (MTL). Importante citar também, que nesse período temos a realização do Fórum Nacional pela Reforma Agrária e Justiça no Campo, e deste resulta a conhecida Carta da Terra, em defesa da reforma agrária e da agricultura familiar.

Embora o Plano aprovado tenha frustrado as expectativas dos trabalhadores rurais, pois se apresentava como uma proposta intermediária ao que se esperava que era de assentar 1 milhão de famílias, o II PNRA foi negociado com os movimentos sociais e firmou-se um compromisso político junto ao governo federal de que até 2006 seriam assentadas 400 mil novas famílias, sendo 60 mil em 2003; 115 mil em 2004; 115 mil em 2005 e mais 140 mil em 2006.

Diante de tal contexto os ruralistas apresentavam suas insatisfações em relação ao governo e arbitravam todo tipo de estratégia para desbancar a ação dos movimentos sociais. Sua articulação com o Poder Judiciário favoreceu emissão de prisões de muitas lideranças dos movimentos sociais. "Segundo dados da CPT e do MST, até setembro de 2004 foram presos 31 trabalhadores rurais no país, desses, 10 só no estado do Pará”. (ALBUQUERQUE, 2006, p. 105)

Tal fato demonstra que a repressão da luta pela terra e contra a reforma agrária foi uma constante na história do Brasil, principalmente no período da ditadura militar iniciado em 1964, época de um combate odioso das elites e dos militares contra os movimentos sociais e suas lideranças.

Em 2003 os saldos da Reforma Agrária não cumpriram as expectativas de um processo amplo de alteração na concentração fundiária, e no ano que segue o governo não sinalizou a tomada de medidas direcionadas as metas assumidas. Diante de tal fato, o MST, mobilizou e organizou uma jornada de lutas denominada pela imprensa de Abril Vermelho, com objetivo 


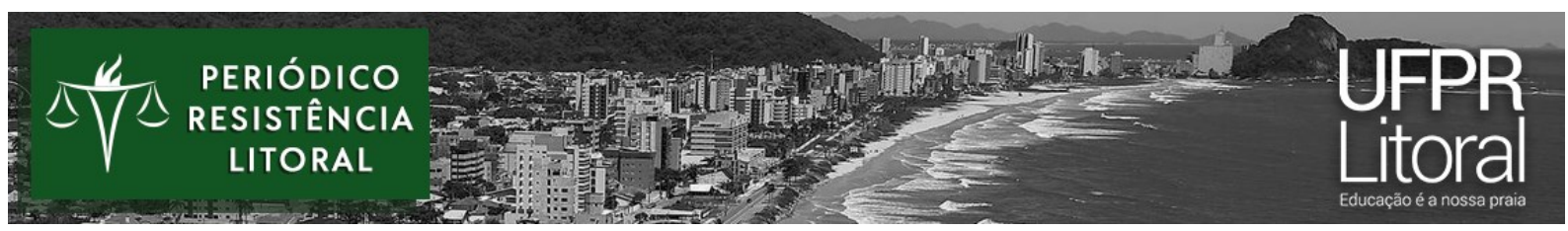

de esclarecer a sociedade sobre o problema da terra e da agricultura no Brasil, e conseguiu concretizar segundo dados do movimento, 127 ocupações de latifúndios em 30 dias.

Entretanto em 2004, segundo Oliveira (2007) os saldos da Reforma Agrária também não foram expressivos. Na mesma lógica dos anos anteriores em 2005, o clima tenso no campo da Reforma Agrária continuava com manifestações e ações dos movimentos sociais. Cita-se a Marcha do MST.

A Marcha do MST reuniu 12 mil integrantes de 22 estados e mais o Distrito Federal. Os trabalhadores partiram de Goiânia com destino a Brasília para exigir do governo Lula o cumprimento das metas da Reforma Agrária e a mudança na política econômica. Outras organizações populares participaram da marcha, como o Movimento dos Pequenos Agricultores (MPA), o Movimento de Mulheres Camponesas (MMC), Movimento dos Atingidos por Barragens (MAB), Conferencia dos Religiosos do Brasil (CRBA) Movimento das Fabricas Ocupadas, além do apoio da Conferência dos Bispos do Brasil (CNBB), entre outras que realizaram atos de apoio à Marcha. (ALBUQUERQUE, 2006, p. 118)

Nota-se diante da conjuntura histórica que ao mesmo tempo em que Lula se comprometeu junto aos trabalhadores rurais sem-terra, também manteve o acordo junto aos latifundiários. Estes últimos pressionavam o governo contra as políticas de desapropriação de terras. Tal fato influenciou o governo a rever suas políticas voltadas ao campo, passando a defender o acesso a terra sob seu controle, ou seja, "sem luta de classe e sem conflitos".

Nesse contexto, a agricultura capitalista, autodenominada de agronegócio, retorna às prioridades da agenda política macroeconômica externa e interna do país. A partir do segundo mandato petista, o Programa de Aceleração do Crescimento (PAC) 43 assumiu o posto de "carro-chefe" do governo e, mais uma vez, a reforma agrária não se afigurou como prioridade na pauta política do Estado. (AZEVEDO, 2012, p. 161)

Tal fator repõe na agenda nacional uma grave e complexa questão agrária. "O agronegócio procura desenvolver políticas de crédito e/ou bolsas de arrendamento, de modo a trazer os ocupantes de terra para o território do mercado". Assim visa convencer os trabalhadores sem-terra de que "o consenso em torno da lógica do grande capital é possível" (FERNANDES, 2008, p. 188)

[...] o MST vai disputar territórios com seu principal oponente: o agronegócio. Essa disputa é uma das principais marcas da questão agrária desde o passado até a atualidade e foi ampliada e intensificada pela modernização e mundialização da produção agrícola. Contraditoriamente, esta nova realidade liberta a reforma agrária da simples compreensão distribucionista e amplia seu conteúdo para uma luta ampla, multidimensional e complexa. Lutar pela reforma agrária significa lutar por todas as 


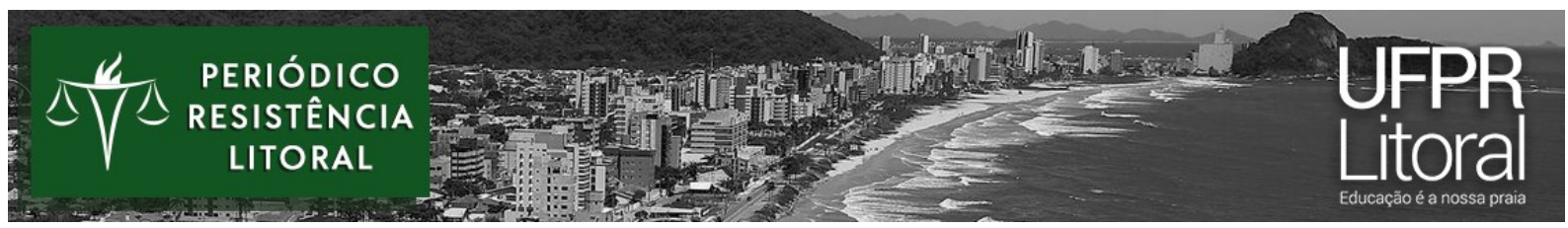

dimensões do território, entre elas a tecnologia, o mercado, a educação, saúde e, principalmente, contra o capital [...] (FERNANDES, 2008, p. 76)

Em 2010 assume a presidência da república Dilma Roussef, a primeira presidenta mulher do Brasil. No que concerne ao tema da reforma agrária brasileira o governo de Dilma não obteve êxito e nem comprometimento com a pauta, sendo que no primeiro mandato foi o governo que menos assentou famílias tomando como referência dados de assentamentos de terra de 1994 a 2014. (INCRA, 2019). Cabe salientar que nos governos Lula e Dilma destacam-

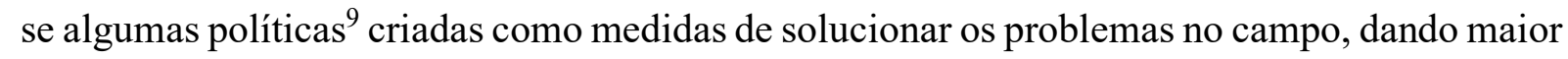
atenção a dimensão social dos assentamentos.

No ano de 2016 vítima de um golpe a presidenta Dilma sofre o impeachment e assume a presidência seu vice Michel Temer e a questão agrária se agrava no País. E algumas ações marcam esse período: a extinção do Ministério do desenvolvimento agrário - MDA, paralisação dos processos de Reforma Agrária e demarcação de terras indígenas dando apoio amplo ao agronegócio e a manutenção das grandes propriedades, aumento da violência no campo, que de acordo com dados do Relatório de violência no Campo da Comissão Pastoral da Terra - CPT no de 2017 registrou 70 assassinatos no campo, sendo o maior número desde 2004.

\section{E AFINAL DE CONTAS...}

Neste escrito procuramos apresentar a questão agrária em seus traços constitutivos, recuperando o seu processo sócio histórico, identificando no contexto brasileiro o embate entre as classes sociais, tendo em vista desvendar as suas múltiplas determinações, embora sabemos que o debate sobre a questão agraria assume diversas correntes interpretativas coletivas, aqui, no entanto nos incumbimos de apresentar "uma" visão sobre esse tema na realidade brasileira.

Diante da história de nossa formação social, é possível constatar que o grande contingente populacional vivendo no campo em condições precárias revela a gravidade da questão agrária na sociedade brasileira. A persistência dos pobres no campo, de populações tradicionais expulsas de seus territórios compondo a pobreza urbana, dos grandes latifúndios de monocultivo está diretamente relacionada à forma de apropriação e exploração da terra e do território, neste caso da exploração capitalista, ou seja, a gênese das desigualdades sociais que

\footnotetext{
${ }^{9}$ Como o programa Luz para todos, PRONAF, PRONERA, Plano Safra, dentre outros.
} 


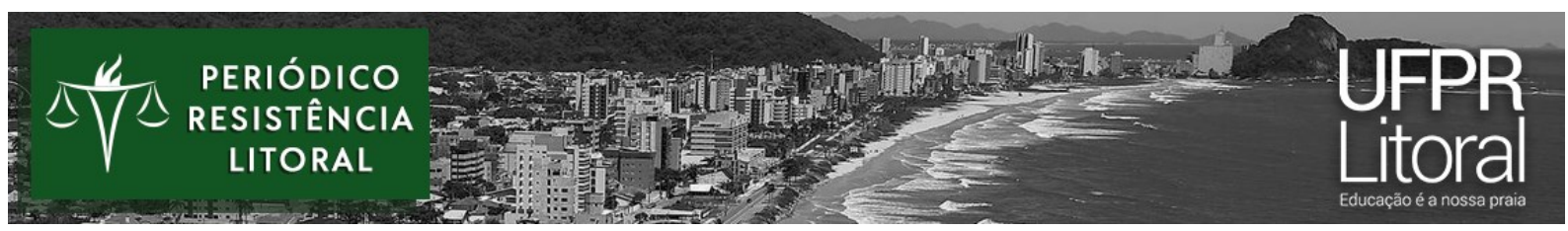

caracterizam o Brasil como uma das sociedades mais injustas do mundo está na relação entre concentração da propriedade fundiária e acumulação de capital; e a presença do elevado desemprego, de trabalhadoras e trabalhadores marginalizados do mercado de trabalho e sem acesso a bens e serviços afirmados como direitos, de povos tradicionais expulsos de seus territórios compondo a pobreza urbana expropriados de sua cultura e forma de vida.

O padrão de organização da agricultura, herança da economia colonial, revelou capacidade notável de resistir à força do tempo e de opor-se a democratização do campo. A histórica e estável estrutura fundiária representa a perfeita harmonia entre latifúndio e modernização técnica, evidenciando a correlação entre a superexploração e o agronegócio. Ao acirrar a busca pela terra, o agronegócio evidencia cada vez mais as contradições e as dicotomias entre pobreza, desmatamento e latifúndio

Assim a questão agrária, a partir de sua relação com o processo de formação das bases materiais do Estado se constitui um problema nacional envolvendo todas as dimensões da sociedade econômica, colocando a reforma agrária como um elemento estratégico de luta com vistas à superação das desigualdades e das relações de poder.

De acordo com Sampaio (2013) a realização da reforma agrária pressupõe forças sociais com capacidade de mobilização para vencer a resistência dos grupos econômicos e sociais que resistem a uma mudança. A reforma agrária é amplamente combatida pelas grandes empresas latifundiárias e pelos segmentos da sociedade que dependem da superexploração do trabalho na cidade e no campo, e para não esquecermos a mídia, que tem papel primordial nesse combate.

Portanto, o papel dos movimentos sociais é primordial para que a luta da terra avance e neste sentido, a luta do MST é apresentada "como um meio (talvez o único) para a conquista da cidadania por milhões de "excluídos"”, mas também, no avanço do projeto "revolucionário" do movimento que não se limita "à simples realização de uma reforma agrária nos marcos do sistema capitalista" (ALMEIDA; SÁNCHEZ, 1998, p. 86).

O MST é o que há de mais vivo nas lutas sociais no Brasil, hoje. A quantos desencontros resistirá? Pagar para ver pode representar um custo político muito elevado para todos os que se empenham em construir, na prática, uma plataforma de lutas que promova um encontro cada vez mais necessário e que, agora, graças em grande parte à atuação do MST, também se revela possível. Não exatamente um encontro de organizações (embora também passe por isso), mas entre as lutas das grandes massas de trabalhadores (empregados ou não) da cidade e do campo (ALMEIDA; SÁNCHEZ, 1998, p. 90). 


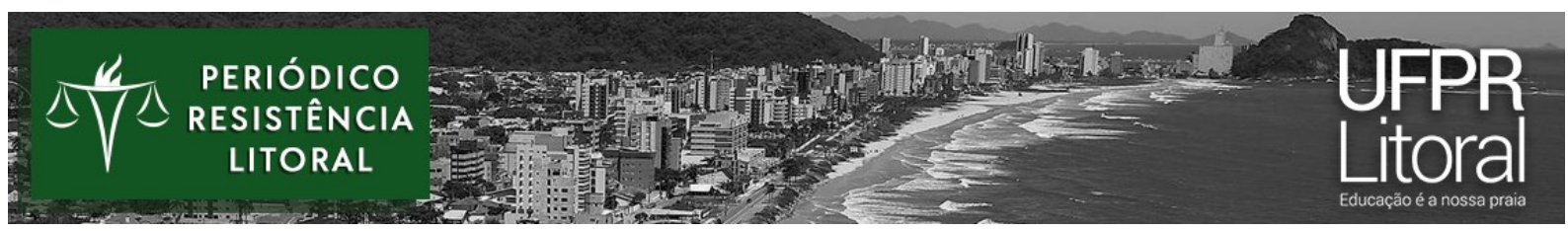

Diante disso é preciso valorizar o potencial de confronto do MST com o capitalismo:

\begin{abstract}
Ao repor os antagonismos que produzem a luta de classes que se tenciona entre um processo de expropriação crescente dos trabalhadores e uma luta mediada pela dialética da resistência que é forjada nesse espaço de luta de classes e disputa de hegemonia. A partir da materialidade da luta nos campos da luta pela terra, reforma agrária e mudanças sociais defendidas pelo MST abriram-se caminhos, mesmo que provisoriamente, que vislumbram, nestes tempos difíceis, possibilidades de unificação de lutas por outro modelo de sociedade. (AZEVEDO, 2012, p. 240)
\end{abstract}

De tal situação verifica-se o enlace das dimensões campo e cidade no Brasil, fator que por si só demonstra a necessidade do desenvolvimento conjunto de políticas públicas e investimento nas duas dimensões, do contrário, o investimento em apenas uma dessas dimensões pode trazer graves consequências agravando cada vez mais a questão social.

Assim, a questão agrária brasileira se constitui nesse processo: a interdição do acesso a terra por parte das populações pobres que não tem condições financeiras de acessá-la, a expansão das fronteiras agrícolas expulsando as comunidades tradicionais de seus territórios, paralelamente, a mão de obra já não é mais tão utilizada nas grandes propriedades e a terra perdeu sua função social sendo transformada em mercadoria, em especulação.

Os dados atuais sobre a estrutura fundiária do país no que tange as terras agricultáveis citada na introdução deste escrito demonstram que tal realidade da distribuição de terras é consequências de um pacto agrário, a riqueza e a terra continuam concentradas nas mãos da oligarquia rural articulada com os interesses do capital industrial e financeiro, tendo o Estado como lócus privilegiado “de conciliação e dos interesses convergentes e divergentes das classes possuidoras e dirigentes do país, e tudo mais, principalmente, as inquietações e implicações sociais, fundiárias e ambientais ficam a margem". (REFORMA AGRÁRIA EM DADOS, 2013)

Diante de tal exposição de acordo com Oliveira (2007), parece que a sina dos que lutam pela reforma agrária, como escreveu Frei Betto em "A Mosca Azul”, tem que ser aquela de nunca poder perder a esperança. Aliás, como ele mesmo escreveu: "A esperança é um pássaro em vôo permanente. Segue adiante e acima de nossos olhos, flutua sob o céu azul, não se lhe opõe nenhuma barreira".

Portanto o problema da reforma agrária e da questão agrária, não será solucionado sem uma intensa reorganização da agricultura em sua forma de ser, sem a demarcação dos territórios tradicionais, preservação das florestas e a eliminação dos grandes latifúndios. Somente assim 


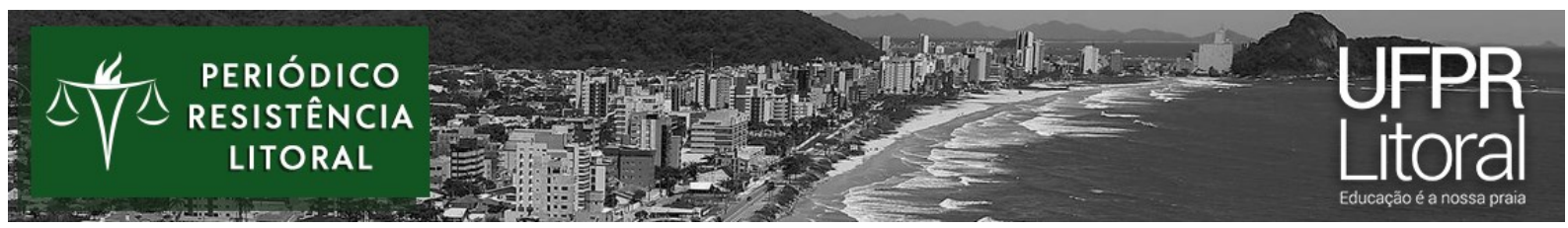

as e os sujeitxs da terra e do território poderão acessar de forma equitativa e digna esse espaço que lhes é de direito.

\section{REFERÊNCIAS}

ALBUQUERQUE, Valéria de Oliveira. Reforma Agrária no governo Lula [dissertação]: uma analise do II Plano Nacional de Reforma Agrária - Franca: UNESP, 2006.

ALMEIDA, Jorge Galdino. Uma História que Poucos Conhecem. Disponível em: $<$ http://www.ligascamponesa s.org.br/?p=101 > Acesso em: 18 jan. 2015.

ALMEIDA, Lucio Flávio de; SÁNCHEZ, Félix Ruiz. Um grão menos amargo das ironias da história: o MST e as lutas sociais contra o neoliberalismo. In: Lutas Sociais. Volume 5. Dez/1998. NEILS - Núcleo de Estudos de Ideologias e Lutas Sociais. PUC/SP

AZEVEDO, Daviane Aparecida de. Da pedagogia da hegemonia burguesa ao difícil caminho de construção de uma contra-hegemonia [dissertação]: O protagonismo do MST nas lutas de resistência no governo Lula.- Florianópolis, SC, 2012.

BASTOS, Fernando. Ambiente institucional no financiamento da agricultura familiar: avanços e retrocessos. Tese (Doutorado em Ciências Sociais) - Universidade Federal do Rio Grande do Norte, Natal, 2006.

BUAINAIM, Antonio; PIRES, Daniela. Reflexões sobre Reforma Agrária e Questão Social no Brasil. In: XI Seminário Nacional do Direito Agrário. São Luiz do Maranhão - MA, 2003.

COSTA, Carolina Rodrigues. Políticas Públicas e lutas sociais no meio rural [dissertação]: dilemas e contradições no PRONAF. Florianópolis, 2013.

DELGADO, Guilherme. A questão agrária no Brasil, 1950-2003. In: JACCOUD, Luciana. Questão social e políticas sociais no Brasil contemporâneo. Brasília: Ipea, 2005.p.51-90.

FERNANDES, Bernardo Mançano. O MST e as reformas agrárias do Brasil. OSAL/ CLACSO. Ano IX No 24 de Outubro de 2008.

IANNI, Octávio. A ditadura do grande capital. Rio de Janeiro: Civilização Brasileira, 1981.

IBGE - INSTITUTO BRASILEIRO DE GEOGRAFIA E ESTATÍSTICA. Censo agropecuário de 2017. Disponível em: https:/censos.ibge.gov.br/agro/2017/resultados-censoagro-2017.html> acesso em 01 de setembro de 2021. 


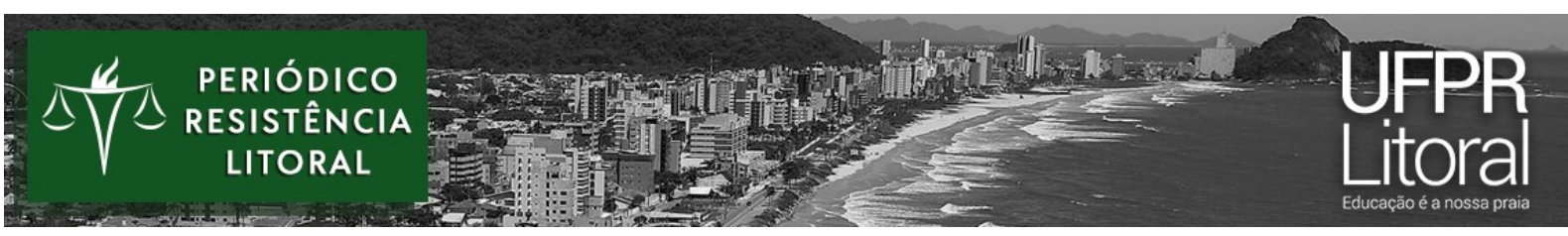

LEAL, Giuliana Franco. Políticas de reforma agrária contra os movimentos sociais de luta pela terra: uma análise dos anos 90. Seminário Nacional Estado e Políticas Sociais no Brasil. Foz do Iguaçu - PR, 2002.

MARTINS, José de Souza. Reforma Agrária: o impossível diálogo. São Paulo: Editora USP, 2000.

OLIVEIRA, Ariovaldo Umbelino. Modo de Produção Capitalista, Agricultura e Reforma Agrária. São Paulo: Labur Edições, 2007.

PRADO JUNIOR, Caio. A questão agrária no Brasil. 3. ed. São Paulo: Brasiliense, 1981.

PRADO JUNIOR, Caio. A questão agrária no Brasil. 4. ed. São Paulo: Brasiliense, 1985.

SANTOS, José Ronaldo. Estudo sobre a questão agrária e a luta pela terra no Brasil: Das lutas messiânicas ao combate ao agronegócio, fev. 2009. Disponível em: $<$ http://www.mst.org.br/node/6477>. Acesso em: 01 de set. 2021.

SANTOS, Josiane. Questão Social. São Paulo, Cortez, 2012.

SILVA, José Graziano. O que é questão agrária. São Paulo: Brasiliense, 1981.

STÉDILE, João Pedro (org). A questão agrária no Brasil. Programas de reforma agrária: 1946-2003. 1. ed. - São Paulo: Expressão Popular, 2005.

STÉDILE, João Pedro (org). A questão agrária no Brasil. O debate tradicional: 1500-1960.

2. ed. - São Paulo: Expressão Popular, 2011. 